\title{
Paradox of Rice Seed System in India
}

\author{
S.K. Mosharaf Hossain*, Swati Nayak \\ International Rice Research Institute, Bhubaneswar Office, India \\ *Corresponding Author (Email: s.hossain@irri.org)
}

How to cite this paper: Hossain, S.K.M. and Nayak, S. (2020). Paradox of Rice Seed System in India. Grassroots Journal of Natural Resources, 3(1): 29-35. Doi: https://doi.org/10.33002/nr2581.6853.03013

Received: 15 January 2020

Reviewed: 25 February 2020

Provisionally Accepted: 28 February 2020

Revised: 12 March 2020

Finally Accepted: 19 March 2020

Published: 31 March 2020

Copyright $(2020$ by author(s) and The Grassroots Institute.

This work is licensed under the Creative

Commons Attribution International

License (CC BY 4.0).

http://creativecommons.org/licenses/by/4.0/
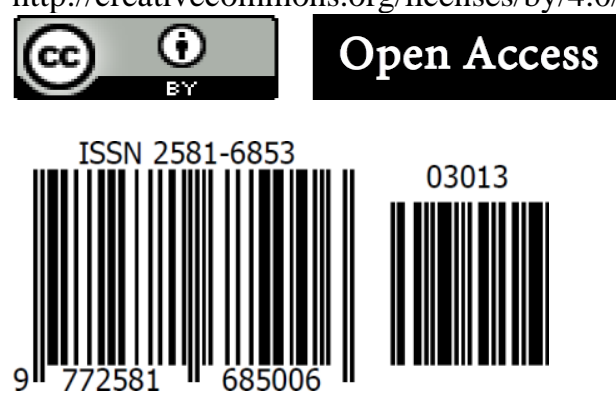

\begin{abstract}
Importance of rice in agrarian economy of India is enormous. In order to meet demand of this staple crop for increasing population, productivity enhancement is a key research and development agenda. Improving seed replacement rate is widely held as a critical area to boost rice productivity in the country. This study based on secondary data revealed merely sowing quality seeds may not result in desired level of yield increase unless quality seeds of a good and appropriate variety is sown. Punjab, with its $38 \%$ SRR, registers 3.97 ton per ha yield whereas it is just 1.51 ton per ha in Chattisgarh where SRR is $44 \%$. There are many varieties, quite older than stipulated 10 years, that are largely indented and grown due to lack of substitutes and poor varietal awareness. Because of this slow varietal awareness and replacement, rice yield still stagnates despite seeds are of assured quality. This shows varietal replacement rate is as important as seed replacement rate. The available studies also indicate that current seed system further needs to rationalize variety selection, production and multiplication of breeder seeds for ensuring seed security of farmers and this should be supplemented by measures taken to promote varietal promotion and replacement, quality seed production interventions at farmers' level, and decentralized seed production system.
\end{abstract}

\section{Keywords}

Seed replacement rate, Variety replacement rate, Seed production, Seed security 
Doi: https://doi.org/10.33002/nr2581.6853.03013

\section{Introduction}

As a rice eating country of 1.3 billon population, growing at $1.01 \%$ annually (Anonymous, 2019a), India needs secured supply of rice to maintain self-sufficiency in its food security mission. Despite having made many commendable strides in boosting agricultural production, per capita food grains availability in the country was just $178 \mathrm{~kg}$ per annum in 2016, which does not compare well with achievements of USA (1100 kg), China (450 kg) and Bangladesh (200 kg) (Anonymous, 2019b). Per capita rice availability in the country increased from $58 \mathrm{~kg}$ to $68.8 \mathrm{~kg}$ during the period of 1951 to 2009 (Rao, 2015). Since there will be growing requirement of rice in future for obvious reason, rice production must keep its pace proportionately to ensure availability dimension of food security. But several rice yields limiting factors pose real challenges to researchers and policy makers to boost production significantly. This is more relevant as rice makes up approximately $44 \%$ of total food grain production in the country and this cereal alone brought home a 5.77 billion USD through export in 2017 (Chauhan et al., 2017).

Between 2001-02 and 2014-15, recorded growth rate in the yield was just 15\% with instability of 9\% (coefficient of variation). Among many others, quality seed is a critical input for yield stabilization and productivity enhancement in many food crops like rice. This is the wellestablished perception and being pursued by development and research practitioners, as several studies conclusively revealed that quality seed alone can contribute to $15-20 \%$ of total production and can be further raised to $45 \%$ depending on the crops. Food security is heavily interlinked and dependent on seed security of the farming community. While this is largely a true connotation, there is more into this spectrum. It is not only quality seed but quality seed of improved varieties that actually matters to reverse stagnant rice yield in India.

\section{Seed replacement scenario in rice}

While 100\% SRR (proportion of area covered under quality/certified seeds) is strongly recommended for rice being a self-pollinated crop, scientists suggest there should be at least 33\% seed replacement rate to maintain quality of seeds sown. India, a country with higher rate of seed replacement rate reveals greater usage of quality (certified seeds); therefore, crop productivity is naturally to be on the higher side. But trend and story of India are full of contradictions. For instance, in the year of 2015-16, SRR in India was 39.81, which corresponds the yield of merely 2.4 ton per hectare. When we further delve into interplay of SRR and yield of 15 major rice producing states in India, some emergent facts come out that have a different tale to tell. The state of Punjab, harbinger of green revolution, registers highest rice productivity (3.97 ton per hectare), but SRR is just 38\%. Andhra Pradesh and Telangana, the major hybrid rice growing states with highest SRR (89\%) in the country, produce average yield of 3.47 and 2.91 ton per hectare, respectively; and these yields are lower than Tamil Nadu, which is able to produce 3.76 ton per ha with 64\% SRR. Assam and Chhattisgarh have almost similar SRR (42\% and 44\%, respectively), but yield of rice in Assam (2.06 ton per ha) is higher than that of Chhattisgarh (1.51 ton per ha). Haryana, another major rice producing state, ranks fourth in rice productivity (3.06 ton per ha) with just 32\% SRR. Likewise, West Bengal registered a modest yield of 2.89 ton per ha even though $\mathrm{SRR}$ is $37 \%$. Even a simple correlation computed between yield and SRR is just 0.47 indicating a poor association. 


\section{YIELD VS SRR IN MAJOR RICE PRODUCING STATES OF INDIA (2015)}

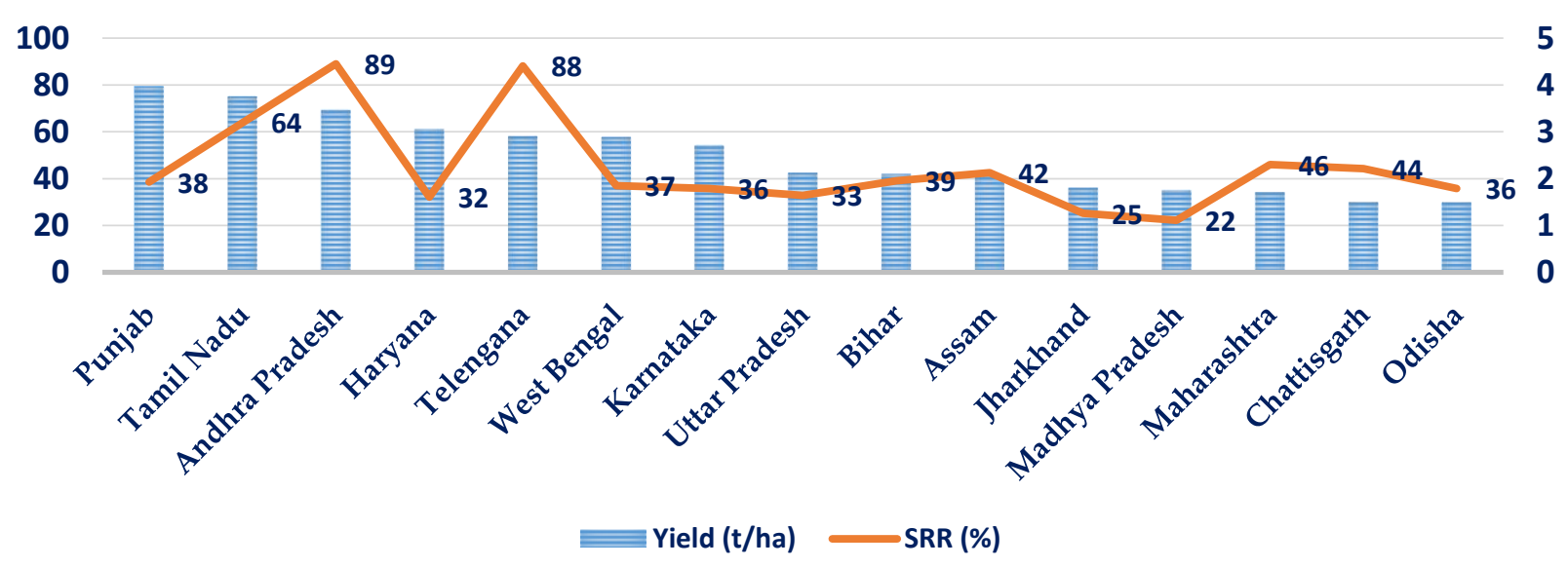

Figure 1: Rice productivity vis-à-vis seed replacement rate of different states in India (Anonymous, 2019c)

Table 1: Year wise seed replacement rates (\%) of major rice producing states (Anonymous, 2019c)

\begin{tabular}{|l|l|l|l|l|l|l|l|l|l|l|l|l|l|l|}
\hline $\begin{array}{l}\text { Major rice } \\
\text { producing state }\end{array}$ & $\mathbf{2 0 0 3}$ & $\mathbf{2 0 0 4}$ & $\mathbf{2 0 0 5}$ & $\mathbf{2 0 0 6}$ & $\mathbf{2 0 0 7}$ & $\mathbf{2 0 0 8}$ & $\mathbf{2 0 0 9}$ & $\mathbf{2 0 1 0}$ & $\mathbf{2 0 1 1}$ & $\mathbf{2 0 1 2}$ & $\mathbf{2 0 1 3}$ & $\mathbf{2 0 1 4}$ & $\mathbf{2 0 1 5}$ & $\mathbf{2 0 1 6}$ \\
\hline Punjab & 23.0 & 15.0 & 19.0 & 21.0 & 24.0 & 21.0 & 27.8 & 40.1 & 52.8 & 33.2 & 40.4 & 37.6 & 38.5 & 35.7 \\
\hline Tamilnadu & 14.0 & 12.0 & 55.0 & 56.0 & 65.0 & 67.0 & 76.7 & 62.7 & 68.0 & 76.0 & 68.4 & 70.6 & 63.9 & 63.1 \\
\hline Andhra Pradesh & 49.0 & 52.0 & 61.0 & 60.0 & 73.0 & 82.0 & 81.8 & 86.5 & 87.2 & 88.3 & 85.8 & 85.5 & 89.0 & 85.0 \\
\hline Haryana & 14.5 & 14.1 & 17.0 & 17.5 & 18.0 & 17.9 & 18.5 & 21.7 & 30.5 & 31.5 & 31.1 & 30.4 & 32.1 & NA \\
\hline West Bengal & 25.0 & 25.3 & 25.5 & 26.0 & 26.5 & 28.0 & 30.0 & 32.0 & 33.7 & 34.0 & 35.0 & 36.8 & 36.9 & 38.0 \\
\hline Karnataka & 25.0 & 30.3 & 29.0 & 34.0 & 36.0 & 33.0 & 38.9 & 40.9 & 71.8 & 40.4 & 35.5 & 35.7 & 35.8 & 38.3 \\
\hline Uttar Pradesh & 17.3 & 17.9 & 20.3 & 22.7 & 25.0 & 28.6 & 28.4 & 37.8 & 31.6 & 33.7 & 34.8 & 33.0 & 32.8 & 34.0 \\
\hline Bihar & 6.8 & 10.0 & 12.0 & 12.0 & 15.0 & 19.0 & 35.2 & 41.7 & 38.0 & 40.2 & 40.8 & 38.8 & 39.1 & 42.9 \\
\hline Assam & NA & 3.0 & 6.8 & 10.7 & 17.3 & 23.0 & 32.4 & 46.5 & 46.8 & 47.9 & 31.1 & 34.5 & 42.5 & 42.5 \\
\hline Jharkhand & NA & NA & NA & NA & NA & 14.3 & 23.4 & 25.1 & 17.1 & 25.0 & 15.7 & 15.4 & 25.2 & 13.9 \\
\hline Madhya Pradesh & 3.9 & 3.4 & 6.4 & 4.0 & 8.9 & 10.1 & 15.6 & 13.3 & 16.9 & 19.6 & 22.6 & 24.0 & 22.2 & 26.9 \\
\hline Maharashtra & 19.0 & 20.0 & 19.0 & 24.0 & 30.0 & 42.0 & 42.0 & 44.1 & 45.9 & 47.8 & 44.7 & 45.1 & 46.0 & 47.0 \\
\hline Chhatisgarh & 2.5 & 5.9 & 7.2 & 8.5 & 7.7 & 13.8 & 20.4 & 28.4 & 34.3 & 36.4 & 40.3 & 43.3 & 44.3 & 67.9 \\
\hline Odisha & 6.1 & 4.7 & 6.8 & 6.4 & 12.0 & 14.8 & 19.1 & 20.6 & 21.7 & 22.2 & 30.6 & 31.6 & 35.8 & 32.7 \\
\hline All India & $\mathbf{1 9 . 2}$ & $\mathbf{2 3 . 3}$ & $\mathbf{2 4 . 4}$ & $\mathbf{2 2 . 4}$ & $\mathbf{2 5 . 9}$ & $\mathbf{3 0 . 1}$ & $\mathbf{3 3 . 6}$ & $\mathbf{3 7 . 5}$ & $\mathbf{3 7 . 9}$ & $\mathbf{3 9 . 1}$ & $\mathbf{5 7 . 6}$ & $\mathbf{3 2 . 8}$ & $\mathbf{3 6 . 8}$ & $\mathbf{3 9 . 8}$ \\
\hline
\end{tabular}

\section{Varietal replacement is as important as seed replacement}

The yield of any crop is resultant of a combination of factors where seed is critically important. Quality of seeds largely determines responses of other factors of production. So, in order to use seed as a more contributory determinant, it must be not only of good quality but also of a best variety. Therefore, quality seed alone may not make much difference in the productivity until it comes from a good and suitable variety. Now, what actually a good variety denotes? Practically speaking, a variety should not be more than 10 years old, which is suitable and recommended for a specific rice ecology. Does the system provide farmers good varieties of seeds with assured quality? In fact, VRR (variety replacement rate) coupled with SRR (seed replacement rate) holds the key to boost the rice productivity. However, many of the ongoing productivity enhancement 
programs are obsessed with SRR, and insufficient efforts are directed to replace older varieties. This is evident from the varieties (breeder seeds) indented by different states of India. To cite an example, in the year of 2014-15, all states together put their indent for 219 varieties with a total quantity of 428 tons. Of these indented varieties, only 110 are new and meet criterion of being 10 years old. These 110 varieties make up a demand of 181 tons, only $42 \%$ of total demand. This excludes demand of hybrid varieties, which constitutes only a fraction of total quantity of breeder seed indented. Average age of varieties in the list of breeder seed indent is 15.21 years, much higher than stipulated period of 10 years. MTU 7029, CR 1009, Lalat, IR 64, Gayatri and Parijat, to name few, are the varieties that are 25 years old. Jaya is another variety introduced in seed chain in the year of 1969, which is still demanded by states like Maharashtra and Karnataka. IR 36, a 33 years old variety, still make it to the list of breeder seed indent. Genetic erosion, susceptibility to diseases and pests, and some unwanted traits start developing in a variety if cultivated after 10 years time. For this obvious reason, even though quality seeds of these older varieties are used, desired yield may not be realised. Needless to say, these older varieties must be replaced with matching newer varieties that are available through varietal development programs. This explains why varietal replacement is as important as seed replacement.

\section{Story of breeder seeds}

Provisioning of breeder seed to seed provider bodies is instrumental for the multiplication of indented varieties. Breeder seeds, after having multiplied for 2-3 cycles, reach farmers as certified seeds. Conventionally, state agriculture departments indent for breeder seeds from Ministry of Agriculture and Farmers' Empowerment, which, in turn, directs Indian Council of Agriculture Research (ICAR) to prepare a seed plan as per the indented demand (Rao, 2015). When these varieties are harvested and ready, state agencies are asked to lift those seeds primarily for multiplication purpose. Table 2 presents quantity of breeder seeds indented and produced. Between 2011 and 2016, production of breeder seeds exceeds the demand (Pathak et al., 2018). So, it can be safely assumed there is no production constraint of breeder seeds. There are instances when a portion of indented demand was never lifted by state government or other agencies. In the year of 2015-16, a total of 502.6 ton of seeds was demanded and 544.9 ton was produced; and 51.52 ton was not lifted (Pathak et al., 2018).

The area under rice in 2016-17 was 43.99 million hectares for which 2.2 million tons seeds is sufficient with average seed rate of $50 \mathrm{~kg}$ per ha. Breeder seeds indented for production in 201415 was sufficient to meet this demand of 2.2 million tons certified seed requirement (Anonymous, 2019c). Ironically, SRR in rice is just 30\% in India. This brings forth glaring inefficiency of seed multiplication and distribution system of the country. Inefficient seed multiplication, weak distribution network and mismanagement of breeder seeds are bottlenecks that explain this paradox in rice seed system of India. This clearly presents a fact that breeder seeds that demand greater resources and efforts for production go waste when lifted seeds are not utilized appropriately for multiplication. The very essence of this process to make certified seeds available to farmers is diluted. 
Doi: https://doi.org/10.33002/nr2581.6853.03013

Table 2: Breeder seed production and utilization over the years (Anonymous, 2019c)

\begin{tabular}{|c|c|c|c|c|}
\hline Year & Rice Area $m$ ha & Breeder seed indented (q) & Production (q) & Non lifting (q) \\
\hline $2011-12$ & 44.01 & 5772 & 6828 & NA \\
\hline $2012-13$ & 42.75 & 5267 & 11455 & NA \\
\hline $2013-14$ & 44.14 & 4837 & 10586 & 289.2 \\
\hline $2014-15$ & 44.11 & 4286 & 7757 & 212.7 \\
\hline $2015-16$ & 43.50 & 5026 & 5449 & 515.2 \\
\hline $2016-17$ & 43.99 & 5119 & 8765 & NA \\
\hline
\end{tabular}

\section{Slow rate of adoption of modern varieties}

Slow technology diffusion in agriculture is a chronic issue owing to interplay of a host of reasons ranging from sub-optimal extension system or infrastructure constraints to poor science communication with farmers. Standard norm is a variety older than 10 years from the date of notification should be strongly discouraged because of its falling quality. In pursuance of discontinuing such older varieties, many states stop seed subsidy. But there is a stark fallacy in terms of harnessing full potential of the variety. For instance, Swarna sub 1 variety has been bred as a substitute of popular mega variety Swarna. After 10 years of its notification, adoption rate of Swarna sub 1 is quite less. There is still a lot of scope to diffuse this variety where it is required most. So, as per the norm, should this Swarna sub 1 be discontinued or made non-subsidized? If this is done so, further adoption of this variety will be discouraged; therefore, full potential of Swarna sub 1 may not be realized. This also means poor return on investment is made in breeding program to develop this variety.

\section{Varietal identity and genetic purity}

Presently, seed testing laboratory follow protocols and procedures prescribed by International Seed Testing Association (ISTA) to measure genetic purity, but varietal identity area has enough room for further modernization. Current practice of grow out test is not only ineffective but also time consuming and laborious. Many a times, a variety in an area for long does not satisfactorily match the genetic map of the original variety. Therefore, genetic identity is a challenge for older varieties for which DNA fingerprinting has not been done during release of the variety.

\section{Improvement areas for a robust seed system}

\section{Thrust should be on timely varietal replacement}

Farmers should have plenty of varietal choices. Breeding program, therefore, should be strengthened accordingly. Sahabhagidhan, a highly recommended variety in uplands of Jharkhand and Odisha where enough soil moisture is a limitation, is almost 10 years old since it has entered into seed chain. However, current breeding program has not been able to make any major breakthrough that offers a possibility to replace this variety. Same is the case for Swarna sub 1, where sub 1 gene was introgressed in the year of 2009 to make it flash floods tolerant. But, no better replacement has been developed yet which can substitute Swarna sub 1. Therefore, breeding programs should target specific rice ecology and direct its efforts developing best suited varieties. 
Recent advancements in breeding program like smart breeding, speed breeding, RGA, etc. to be established, promoted and practiced for timely substitutes of varieties.

\section{Quality seed production for replacing older varieties}

In order to enhance rice productivity, quality seed production initiative is a major program response from many state governments (Chauhan et al., 2016). However, a comprehensive approach has to be adopted where QSP is promoted amongst farmers in conjunction with varietal replacement. No subsidy for a variety older than 10 years should be strictly followed. Additionally, current state system of delivering seeds is not sufficient and efficient to cater the needs of total quantity of seeds. It is, therefore, extremely important that state departments lay emphasis on QSP initiative for newer potential varieties instead of older varieties. In a country where $85 \%$ farmers fall in the bracket of small and marginal category, low cost seed storage technologies should get attention and priority. Excess moisture is the greatest enemy to maintain quality of seeds for the use in subsequent season since very few farmers can afford high-tech seed storage facilities. It is, therefore, imperative to scale up proven technologies like low cost IRRI super bag that empowers farmers with a better seed storage facility.

\section{Decentralization of seed production}

State governments in India distribute seven million quintals of certified rice seeds every year. But this covers only a part of 44 million hectare of rice area. The capacity of state machinery is also limited in respect of extending its seed availability to total rice area. Therefore, decentralization of seed production is an important option for promoting quality seeds among farmers. State agriculture department, through its vast network of technical experts, should plan for capacity building of farmers so that they can produce quality seeds for their own requirement. This will enhance farmers' capacity and boost seed security; thus, it will minimize the burden on state seed corporation or department of agriculture.

\section{Robust seed multiplication strategy}

Production and distribution of quality seeds are primary responsibilities of the state government. Each state and other seed multiplication agencies should formulate and implement a robust seed multiplication system where breeder seeds are appropriately utilized to convert into certified seeds for the supply to farmers. State seed corporation, department of agriculture and cooperatives are involved in organizing production of certified seeds from indented breeder seeds. Over-indenting beyond the capacity of converting breeder seed to next foundation and certified seeds must be avoided to reduce extra burden on the breeder seed producing institutions. A control over this practice is important for maintaining the supply of breeder seed of high quality. A strong production plan and monitoring system developed by state agencies should be in place for strict supervision of seed conversion. State machinery will also need to build a strong chain of dealers for timely procurement and sale to the farmers. This will firm up the system by ensuring an efficient multiplication strategy. 


\section{Mechanism to be strengthened to promote potential varieties}

Full potential of a variety is to be realized during its life length. In order to achieve this, a new variety has to reach to farming community in quickest possible time. Here comes the importance of a vibrant extension system which will be instrumental in popularizing and creating farmers' demand for demonstrated varieties. Innovation in demonstration like varietal cafeteria, head to head trial, cluster demonstration, triadic trials, etc. are to be contextualized and implemented strategically by state extension machinery. The integrated network of state department of agriculture, KVK (Krishi Vigyan Kendra), ATMA (Agriculture Technology Management Agency), state agriculture universities, national research centres proved to be immensely important in improving existing extension approaches. A considerable number of well performing varieties are developed and being disseminated by private companies. State government through its arm of agriculture department needs to validate the worth of those varieties and encourage private players to boost uptake.

\section{Molecular tools for varietal identity and genetic purity}

Molecular identification of genetic purity and varietal identity is time saving and cost-effective option, and can be explored to modernize the system. More resources and efforts are required in this area.

\section{Conclusion}

The farmers should sow the best available varieties with assured quality parameters. Hence the recent obsession of QSP initiative must be coupled with rationalized replacement of older varieties to reap maximum possible yield gain. This is, undoubtedly, to be backed by a robust breeding and seed multiplication program. This strategic shift in approach will support and contribute to country's endeavour of achieving food security and enabling farmers with better economics of rice farming.

\section{References}

Anonymous (2019a). https://www.statista.com/statistics/271308/population-growth-in-india/

Anonymous (2019b). https://www.downtoearth.org.in/news/food/india-claims-to-be-selfsufficient- in-food-production-but-facts-say-otherwise-62091

Anonymous (2019c). https://seednet.gov.in/Material/IndianSeedSector.htm

Chauhan, J.S., Prasad, R.S., Pal, S., Choudhury, P.R. and Udayabhaskar K. (2016). Seed production of field crops in India: Quality assurance, status, impact and way forward. Indian Journal Agricultural Sciences, 86(5): 564-570.

Chauhan, J.S., Prasad, S.R., Pal, S. and Choudhury, P.R. (2017) Seed Systems and Supply Chain of Rice in India. Journal of Rice Research, 10(1): 9-15.

Pathak, H., Nayek., A.K., Jena, M., Singh, O.N., Samal, P. and Sharma, S.G. (2018). Rice Research for Enhancing Productivity, Profitability and Climate Resilience. ICAR-National Rice Research Institute, Cuttack, Odisha, India. Pp.2-44.

Rao, Y.Y. (2015). Rice Seed Production Scenario in India. Directorate of Rice Research, Hyderabad. Pp.4-16. 